\title{
MATERNAL CARE IN LABIDOMERA SUTURELLA CHEVROLAT (COLEOPTERA: CHRYSOMELIDAE: CHRYSOMELINAE) FROM COSTA RICA
}

\author{
By JAE C. CHOE* \\ INTRODUCTION
}

In subsocial insects one or both parents provide postovipositional parental care (Michener 1969). Parental care is the most primitive form of sociality in insects and has evolved independently in diverse orders (references in Wilson 1971, Eickwort 1981, Hinton 1981, Tallamy and Wood 1986). In Coleoptera, it has been observed in only 11 families (Hinton 1981). All four species of Chrysomelidae that have been reported to exhibit subsocial behavior belong to the subfamily Cassidinae (Windsor 1987). I here report the first record of subsociality in Labidomera suturella Chevrolat, a member of the subfamily Chrysomelinae.

\section{MeTHODS}

Aggregations of L. suturella were located and observed in the Organization for Tropical Studies (OTS) field station at Finca La Selva, Costa Rica, during 4-9 July 1984 and 11-17 August 1985. The beetles were feeding on leaves of Witheringia heteroclita (Solanaceae). The numbers of females noted for guarding their larvae in 1984 and 1985 were 4 and 14, respectively. After a period of behavioral observation in 1985,10 females were removed from larvae to assess the selective advantage of parental care. The beetle was identified by Henry Stockwell, Smithsonian Tropical Research Institute, and the plant by William Haber. Voucher specimens of $L$. suturella are in the Museum of Comparative Zoology, Harvard University.

*The Biological Laboratories, Department of Organismic and Evolutionary Biology, Harvard University, Cambridge, MA 02138, USA, and Smithsonian Tropical Research Institute, Apartado 2072 Balboa, Republic of Panama.

Manuscript received by the editor December 22, 1988. 


\section{Results AND Discussion}

Only females provided parental care in L. suturella. Males were present on the same host plants, but were not seen to participate in caring for larvae. Each female guarded one to four larvae (mean $\pm \mathrm{SD}=2.6 \pm 0.7 ; \mathrm{n}=18$ females). The number of eggs laid by females, and whether eggs are maternally protected remain unknown.

Labidomera suturella females always sat over or close by their larvae on the upper surface of the leaf (Fig. 1). Whenever any object or organism approached the larvae, the female immediately moved up to the larvae and shielded them tight by holding the leaf with her legs. Unlike subsocial stink bugs (Eberhard 1975), lace bugs (Tallamy and Denno 1981), or treehoppers (Wood 1976), L. suturella females did not show typical aggressive displays such as fanning the wings, jerking the body, or kicking with the legs. The response to various types of disturbances was to simply hold the larvae tighter. The females were not easily displaced by pushing or pulling.

Worker ants of Paraponera clavata often foraged on the same plants, but were never seen attacking $L$. suturella. When females were removed from their larvae, however, seven (25.0\%) of 28 unprotected larvae were picked up and carried by $P$. clavata within four hrs. Twelve larvae (42.9\%) wandered around and eventually dropped to the ground. The rest (32.1\%) disappeared within $24 \mathrm{hrs}$ for unknown reasons. None of the guarded larvae disappeared during this period. No parasitism was observed.

Wilson (1975) views parental care as an evolutionary response to one of two environmental extremes; unusually stressful or unusually favorable environments. He also identifies two environmental parameters, scarce food resources and predation, as the selective forces for the evolution of parental care. Tallamy and Wood (1986) argues that predation and parasitism are the most important selective pressures for subsocial folivores. Predation appears to be a major driving force behind the evolution of subsociality in L. suturella. However, parasitism can not be ruled out, because no female L. suturella with eggs was observed. Parasitism by wasps appears particularly important in the tropics (examples in Eberhard 1975, Edgerly 1987).

Wilson (1971; see also Eickwort 1981, Hinton 1981) has reviewed cases of subsociality in nine orders of insects: Orthoptera, Dermap- 


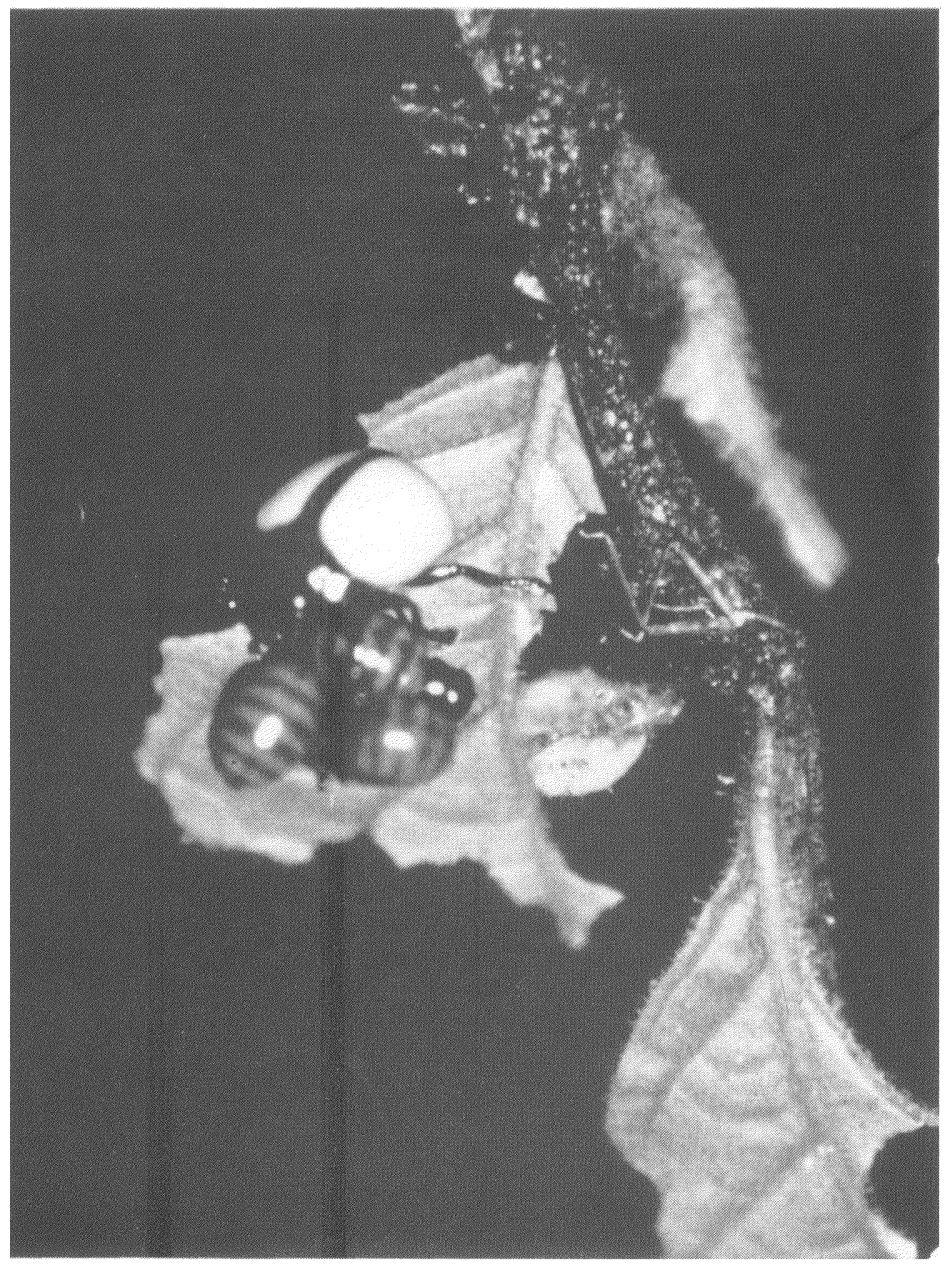

Fig. 1. A female Labidomera suturella guarding her larvae on Witheringia heteroclita. 
tera, Psocoptera, Embioptera, Hemiptera, Homoptera, Thysanoptera, Coleoptera, and Hymenoptera. I have recently noticed that one interesting study has not been included in these reviews. Pages (1967) reported that females of Dipljapyx humberti (Diplura) oviposit at the tip of a stalk, clean eggs, and guard larvae. Also, females of the tropical nymphalid butterfly, Hypolimnas anomala, guard eggs until they hatch and remain with the larvae for one or more days (Nafus and Schreiner 1988). With Diplura and Lepidoptera included, we now have records or subsociality from 11 orders of insects.

\section{SUMMARY}

Subsociality is recorded for the first time from a beetle belonging to the subfamily Chrysomelinae, Labidomera suturella. Females guarded one to four larvae on the upper surfaces of leaves of Witheringia heteroclita (Solanaceae) in La Selva, Costa Rica. Typical defensive behavior of guarding females was to hold the larvae tighter with the legs. When the guarding females were removed experimentally, all larvae were either captured by worker ants of Paraponera clavata, dropped to the ground, or disappeared for unknown reasons within a day.

\section{ACKNOWLEDGMENTS}

I benefited from the critical reviews of Peter Adler, William Eberhard, Bert Hölldobler, Edward Wilson, and Don Windsor. I thank Henry Stockwell and William Haber for identifying the beetle and host plant, respectively. Financial and logistical support from Organization for Tropical Studies and Smithsonian Tropical Research Institute are gratefully acknowledged.

\section{REFERENCES}

EberhaRd, W. G. 1975. The ecology and behavior of a subsocial pentatomid bug and two scelionid wasps: strategy and counterstrategy in a host and its parasites. Smithson. Contrib. Zool. 205: 1-39.

Edgerly, J. S. 1987. Maternal behaviour of a webspinner (Order Embiidina). Ecol. Entomol. 12: 1-11.

Eickwort, G. C. 1981. Presocial insects. In H. R. Hermann (ed.), Social Insects, Vol. 2, pp. 199-280. Academic Press, New York, NY, 491 pp. 
Hinton, H. E. 1981. Biology of Insect Eggs, Vol. 1. Pergamon Press, Elmsford, NY, 473 pp.

MiChener, C. D. 1969. Comparative social behavior of bees. Ann. Rev. Entomol. 14: 299-342.

Nafus, D. M. ANd I. H. Schreiner. 1988. Parental care in a tropical nymphalid butterfly Hypolinmas anomala. Anim. Behav. 36: 1425-1431.

Pages, J. 1967. Données sur la biologie de Dipljapyx humberti (Grassi). Rev. Ecol. Biol. Sol. 4: 187-281.

Tallamy, D. W. AND T. K. Wood. 1986. Convergence patterns in subsocial insects. Ann. Rev. Entomol. 31: 369-390.

Wilson, E. O. 1971. The Insect Societies. Harvard Univ. Press, Cambridge, Mass., 548 pp.

Wilson, E. O. 1975. Sociobiology. The New Synthesis. Harvard Univ. Press, Cambridge, Mass., 416 pp.

Windsor, D. M. 1987. Natural history of a subsocial tortoise beetle, Acromis sparsa Boheman (Chrysomelidae, Cassidinae) in Panama. Psyche 94: 127-150.

Wood, T. K. 1976. Alarm behavior of brooding female Umbonia crassicornis (Homoptera: Membracidae). Ann. Entomol. Soc. Am. 69: 340-344. 

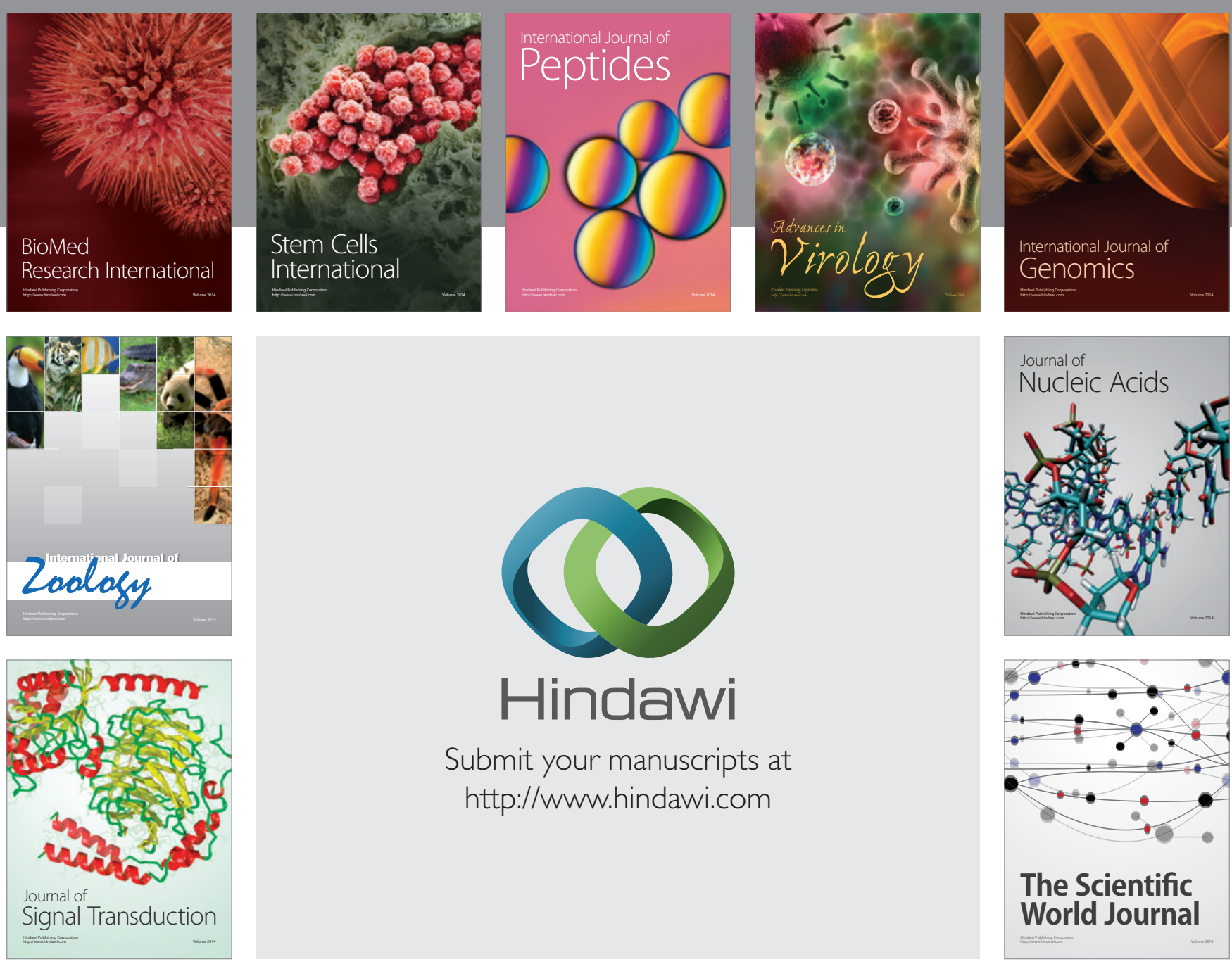

Submit your manuscripts at

http://www.hindawi.com
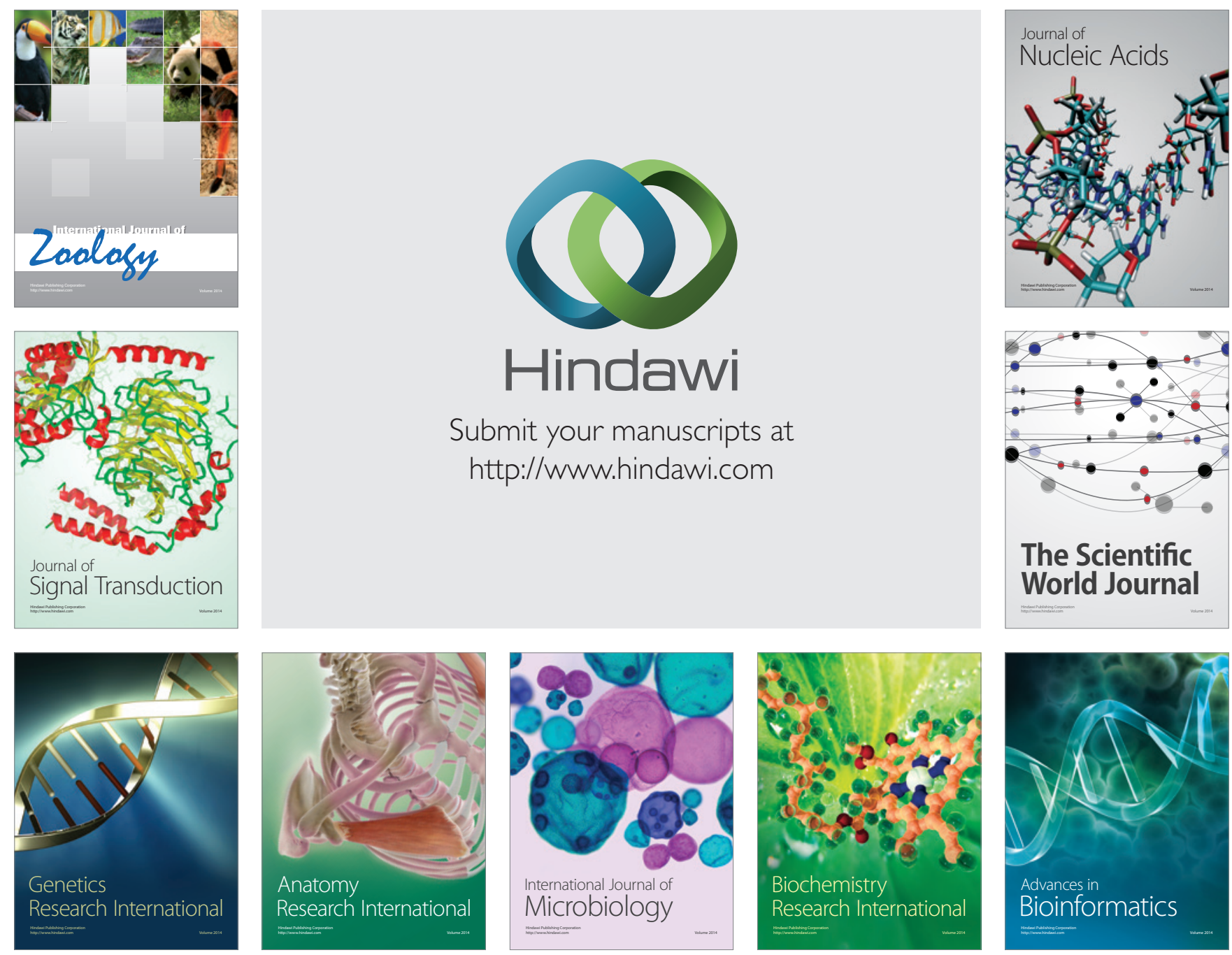

The Scientific World Journal
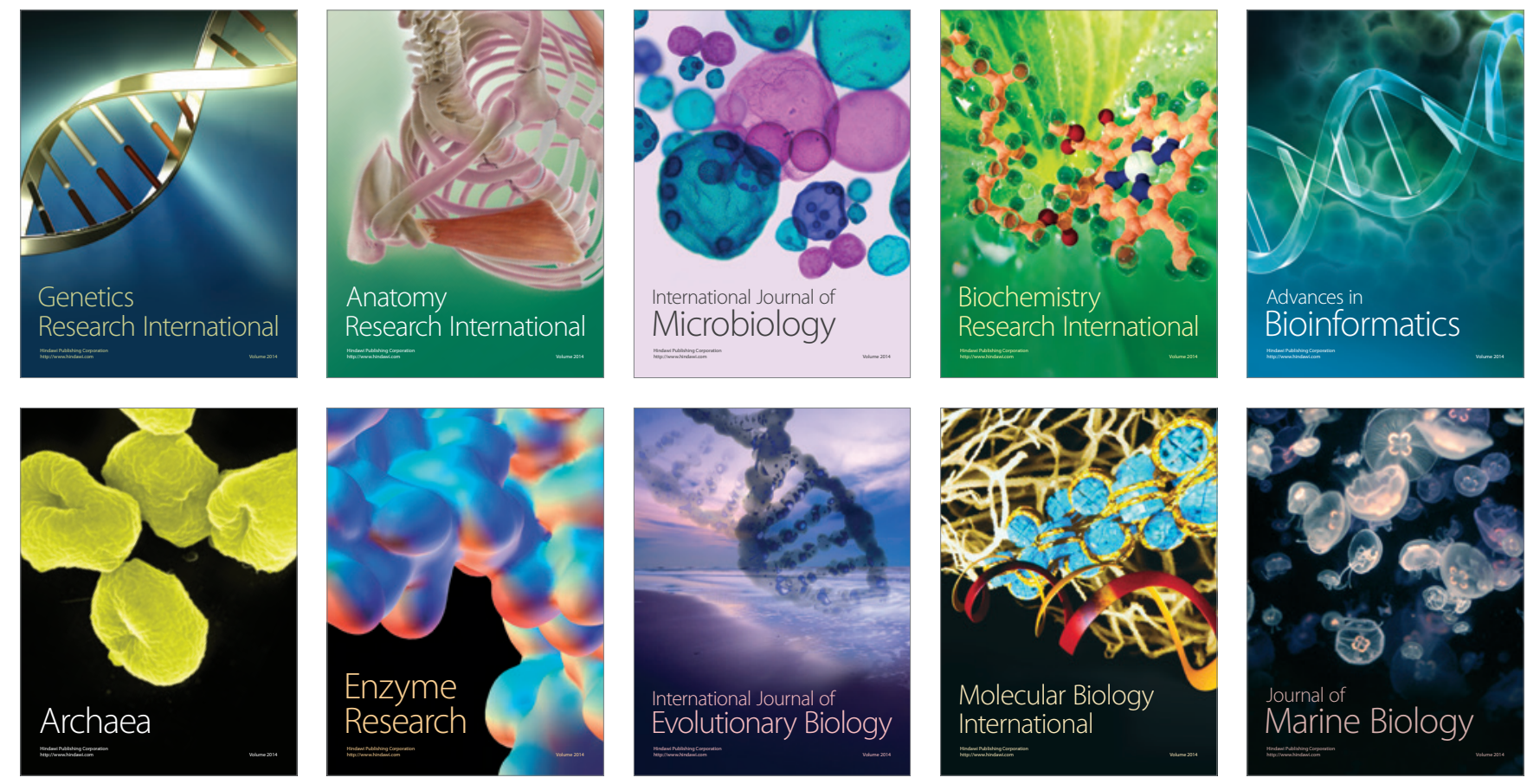